\title{
Commentary: Jack Sprat could eat no fat and his wife could eat no lean
}

\author{
George L. Hicks, MD
}

\author{
From the Department of Surgery, University of Rochester Medical Center, Rochester, NY. \\ Disclosures: Author has nothing to disclose with regard to commercial support. \\ Received for publication July 18, 2019; accepted for publication July 18, 2019; available ahead of print July 25, \\ 2019. \\ Address for reprints: George L. Hicks, MD, University of Rochester Medical Center, 601 Elmwood Ave, Roches- \\ ter, NY 14642 (E-mail: george_hicks@urmc.rochester.edu). \\ J Thorac Cardiovasc Surg 2020;160:423-4 \\ $0022-5223 / \$ 36.00$ \\ Copyright (C) 2019 by The American Association for Thoracic Surgery \\ https://doi.org/10.1016/j.jtcvs.2019.07.020
}

Although intended as a political satire, the nursery rhyme about Jack Sprat and his wife introduces us to a couple with very different levels of dietary indulgences and corpulence, one with excessive weight and the other with little body mass. Indeed, experienced clinicians and surgeons have recognized for years the very different problems that each body habitus presents when decisions are necessary for surgery.

The article in this issue by Nishioka and colleagues, ${ }^{1}$ "Body Mass Index as a Tool for Optimizing Surgical Care in Coronary Artery Bypass Grafting Through Understanding Risks of Specific Complications," is a retrospective analysis of 96,058 patients older than 60 years undergoing coronary artery bypass grafting between the years 2008 and 2012. In a study of data from the Japan Cardiovascular Surgery Database, patients were divided into 4 quartiles according to World Health Organization body mass index (BMI) guidelines: group 1 had BMI less than $18.5 \mathrm{~kg} / \mathrm{m}^{2}$, group 2 had BMI of 18.5 through $24.9 \mathrm{~kg} / \mathrm{m}^{2}$, group 3 had BMI of 25 through $29.9 \mathrm{~kg} / \mathrm{m}^{2}$, and group 4 had BMI of at least $30 \mathrm{~kg} / \mathrm{m}^{2}$. Patients were excluded for previous cardiac surgery and associated other procedures. Nishioka and colleagues ${ }^{1}$ compared these 4 groups for 30 day or in-hospital mortality, as well as postoperative morbidity, which included reoperation for bleeding, stroke, new onset of hemodialysis, mediastinitis, and prolonged ventilation. In their work with 25 preoperative variables and multivariant regression analysis, Nishioka and colleagues, ${ }^{1}$ found that low BMI $\left(<18.5 \mathrm{~kg} / \mathrm{m}^{2}\right)$ and high BMI $\left(\geq 30 \mathrm{~kg} / \mathrm{m}^{2}\right)$ were associated with a higher risk of mortality (low, adjusted odds ratio [aOR], 1.34; 95\% confidence interval [95\% CI], 1.16-1.54; $P<.0001$; high, aOR, $2.10 ; 95 \%$ CI, 1.70-2.59; $P<.0001)$ and combined morbidity (low, aOR, 1.18; 95\% CI, 1.08-1.29; $P=$ .0002 ; high, aOR, 1.82; 95\% CI, 1.63-2.03; $P<.0001)$. Low and high BMIs were associated with different types of morbidities; whereas pneumonia was more common among patients with low BMI, leg wound infection was

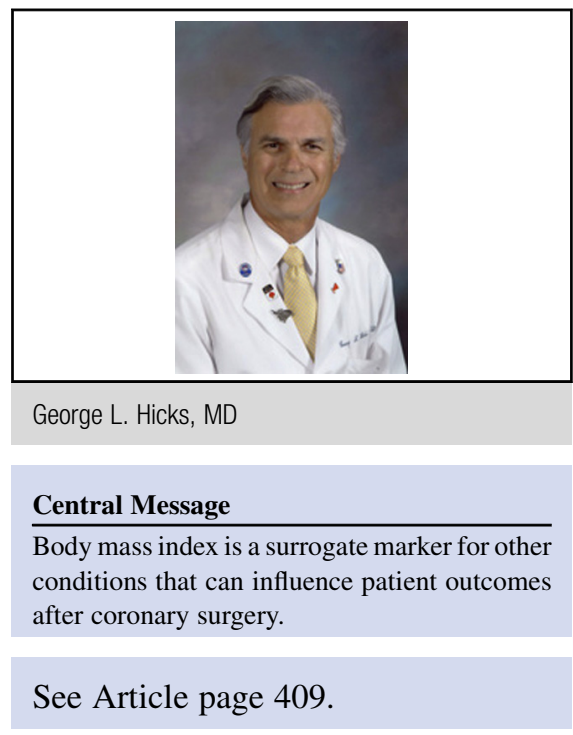

more common among patients with high BMI The study concluded that BMI needs to be considered in the preoperative risk assessment of patients undergoing coronary artery bypass grafting and that, although it is part of the Society of Thoracic Surgeons Predicted Risk of Mortality, it is not included in the euroSCORE but should be included in future iterations.

The study provides the reader with some insight about BMI and differing operative and postoperative mortality and morbidity. I have a number of issues with the use of BMI, however, which I believe is a surrogate marker for other more important variables in the risk assessment of patients undergoing coronary artery bypass grafting.

The 4 groups were very disparate in terms of number within each quartile, and Nishioka and colleagues ${ }^{1}$ have taken a continuous variable and converted it to a static variable. Furthermore, the quartiles, although taken from the World Health Organization, are arbitrary, and subanalysis of each group reveals some significant variances present.

Nishioka and colleagues ${ }^{1}$ pointed out the significant differences in preoperative variables, with group 4 having a higher incidence of diabetes mellitus, whereas group 1 had higher proportions of preoperative intra-aortic balloon pump support, low ejection fraction, congestive heart failure, respiratory failure, renal dysfunction, and emergency situation, as well as a higher frequency of intraoperative transfusion. Nishioka and colleagues ${ }^{1}$ thus were not comparing similar groups, regardless of the BMI differences. 
Further, emaciation is a subjective term, and Nishioka and colleagues ${ }^{1}$ provide no clear data (other than BMI) on these patients. They acknowledged that they did not have albumin or prealbumin, psoas muscle mass, or skin turgor data, which would help us understand the level of cachexia or malnutrition, the better to quantify frailty, which may be more important in this low BMI group.

With regard to postoperative infections, especially leg sites, there is no description in the article regarding the technique for vein removal. Certainly, if open techniques were used in fatty, edematous legs, higher incidences of morbidity would be expected; likewise, in the obese patient with a 3- to 4-inch thick chest wall, the use of bilateral internal thoracic arteries carries both sternal healing issues and possible increased infection risk.

Jack Sprat and his wife do represent unique clinical risks and individual decision making. Currently, a course of preoperative nutrition with physical and pulmonary rehabilitation for the frail patient has been shown to improve postoperative mortality and morbidity, while in the obese patient, careful control of preoperative blood glucose and improvement in hemoglobin $\mathrm{A}_{1 \mathrm{c}}$ levels are associated with lower infection rates and morbidity. Nishioka and colleagues ${ }^{1}$ appropriately point out that current risk calculators do not accurately record many risk factors that can influence mortality and morbidity, but the use of BMI in the quartiles suggested in this article both oversimplifies and complicates the differentiation between poor Jack who could eat no fat and his wife who could eat no lean.

\section{Reference}

1. Nishioka N, Ichihara N, Bando K, Motomura N, Koyama N, Miyata H, et al. Body mass index as a tool for optimizing surgical care in coronary artery bypass grafting through understanding risks of specific complications. J Thorac Cardiovasc Surg. 2020;160:409-20.e14. 